Generation and chromosome mapping of expressed sequence tags (ESTs) from a hu...

Mee-Yul Hwang; Yoon-Joong Kang; Young-Ho Kim; Steve W Scherer; et al Genome; Jun 1999; 42, 3; ProQuest Medical Library

pg. 457

\title{
Generation and chromosome mapping of expressed sequence tags (ESTs) from a human infant thymus
}

\author{
Mee-Yul Hwang, Yoon-Joong Kang, Young-Ho Kim, Steve W. Scherer, \\ Lap-Chee Tsui, and Uik Sohn
}

\begin{abstract}
In an effort to identify novel genes that are expressed differentially in an infant thymus, we constructed an oligo-d(T) primed cDNA library from a human infant thymus followed by single-run partial sequencing to generate expressed sequence tags (ESTs). Characterization of more than 1400 sequences enabled us to convert human thymus transcripts into 1223 useful ESTs. These ESTs consisted of $613(50.1 \%)$ showing homology to known human genes, 51 $(4.2 \%)$ matching to genes from other species, 289 (23.6\%) matching ESTs of unknown functions, and $182(14.9 \%)$ being novel transcripts. The expression profile of an infant thymus features a high number of genes related to cell division-DNA synthesis and gene-protein expression, indicating the active growth stage of an infant thymus. To identify the chromosomal localization of 43 thymus ESTs, PCR-based mapping was performed using a human-rodent somatic cell hybrid or radiation hybrid mapping panel. The results indicated that several novel genes were determined to be located in the vicinity of previously mapped disease loci; histidinemia loci, plasminogen Tochigi disease loci, Ehlers-Danlos syndrome, hypertriglyceridemia, thyroid resistance locus, ocular albinism, galactosemia, porphyria variegata, Charcot-Marie-tooth disease, FEOM (fibrosis of extraocular muscles), Prader-Willi syndrome.
\end{abstract}

Key words: cDNA, expression profile, radiation hybrid mapping, disease locus.

Résumé : Afin d'identifier de nouveaux gènes qui sont exprimés de manière différentielle dans le thymus d'un nouveau-né, une banque d'ADNc provenant du thymus d'un nouveau-né et dont la synthèse a été initiée avec une amorce oligo-d(T) a été produite. Ces $A D N c$ ont ensuite fait l'objet d'une seule réaction de séquençage de façon à générer une collection de séquences exprimées (EST). Une caractérisation de plus de 1400 séquences a permis de convertir des transcrits humains en 1223 EST utiles. Ces EST comprenaient $613(50,1 \%)$ séquences montrant une homologie à des gènes humains connus, $51(4,2 \%)$ étaient homologues à des gènes connus chez d'autres espèces, 289 $(23,6 \%)$ étaient apparentés à des EST de fonction inconnue et $182(14,9 \%)$ correspondaient à de nouvelles séquences. Le profil d'expression d'un thymus de nouveau-né montre un nombre élevé d'expression de gènes impliqués dans la division cellulaire-synthèse de l'ADN et dans l'expression des gènes-protéines, ce qui est le reflet du stade de croissance active du thymus chez le nouveau-né. Afin de déterminer la position chromosomique de 43 EST du thymus, une cartographie a été réalisée à l'aide d'une technique PCR employée sur des hybrides somatiques ou une collection d'hybrides résultant d'irradiation. Les résultats indiquent que plusieurs nouveaux gènes sont localisés à proximité de loci de maladies : des loci d'histidinémie, de la maladie du plasminogène Tochigi, du syndrome d'Ehlers-Danlos, de l'hypertriglycéridémie, de la résistance thyrö̈dienne, de l'albinisme oculaire, de la galactosémie, du porphyra variegata, de la maladie dentaire Charcot-Marie, de la FEOM (fibrose des muscles extraoculaires) et du syndrome de PraderWilli.

Mots clés : ADNc, profil d'expression, cartographie à l'aide d'hybrides résultant d'irradiation, locus de maladie.

[Traduit par la Rédaction]

Corresponding Editor: R.S. Singh.

Received July 8, 1998. Accepted November 11, 1998.

M.-Y. Hwang, Y.-J. Kang, and U. Sohn. ${ }^{1}$ Department of Genetic Engineering, College of Natural Sciences, Kyungpook National University, Taegu, 702-701, Korea.

Y.-H. Kim. Department of Microbiology, College of Natural Sciences, Kyungpook National University, Taegu, 702-701, Korea. S.W. Scherer and L.-C. Tsui. Department of Genetics, The Hospital For Sick Children, Toronto, Ontario, M5G IX8, Canada.

${ }^{1}$ Author to whom all correspondence should be addressed (e-mail: usohn@bh.kyungpook.ac.kr). 


\section{Introduction}

Since ESTs have been used as a starting point for the functional and structural analysis of the entire human genome, many efforts to identify all the human genes have focused on studies of expressed sequence tags (ESTs) generated by single-run partial cDNA sequencing (Kirkness 1996). This large-scale sequencing has not only provided comprehensive information on the expression pattern of a variety of human tissues and cells (Adams et al. $1993 a$, 1993b; Affara et al. 1994; Choi et al. 1995; Frigerio et al. 1995; Hwang et al. 1995; Kawamoto et al. 1996; Liew et al. 1994; Lee et al. 1995; Okubo et al. 1995; Sudo et al. 1994; Tanaka et al. 1996) but has also generated gene-based sequence-tagged sites for rapid large scale PCR mapping (Berry et al. 1995). The utility of EST mapping has been shown by the uncovering of new insights into genome organization, evolution, and expression, as well as by the facilitating of the positional cloning of human genes linked to diseases (Boguski and Schuler 1995; Collins et al. 1995).

The thymus is a central lymphoid organ in the upper chest which is responsible for the development of immunocompetent cells from immature T cells. In 1995, the first report appeared on the generation and chromosomal localization of human adult thymus ESTs from a normalized cDNA library (Lamerdin et al. 1995). In addition, the TIGR collection also reported over 1100 ESTs from primary or substracted cDNA libraries of human adult normal and tumor thymus tissues (Adams et al. 1995). However, there has not been any report on a gene expression profile reflecting the specialized functions and physiological characteristics of the human infant thymus. Accordingly, we describe here the generation and analysis of 1223 ESTs from a human infant thymus, and the chromosome mapping of 43 ESTs using PCR-based mapping strategy.

\section{Methods}

\section{Construction of CDNA library and sequencing}

Total RNA was isolated from a 14 mo old human thymus according to the guanidine thiocyanate method (Sambrook et al. 1989). Poly (A)+ RNA was obtained from total RNA by an oligo d(T)-cellulose column. cDNAs were synthesized using a cDNA synthesis kit (Amersham, U.K.). The cDNAs were anchored with a Not I-EcoRI adaptor and digested by the EcoRI restriction enzyme, and subsequently inserted into an $E c o R I$-digested $\lambda$ ZAPII vector and packaged utilizing a Gigapack gold II packaging system (Stratagen, La Jolla, Cal.). The cDNA library was in vivo excised with a R408 helper phage and transfected into an $E$. Coli strain, XL1-Blue. For sequencing, DNA templates were prepared by the alkaline lysis method (Sambrook et al. 1989). Sequencing reactions were performed with a Sequenase v. 2.0 kit (Amersham, UK).

\section{Database analysis}

Sequences obtained by the single-run partial sequencing were subject to a BLAST search (Altschul et al. 1990) against nonredundant nucleotide and protein databases, as well as dbEst. When the $P$-value of BLAST reports was less than $1.0 \times 10^{-5}$, the sequences were considered as database-matched clones.

\section{Chromosome mapping}

PCR primers were designed by the PRIMER program available on the Web site (http://www-genome.wi.mit.edu). PCR reactions were
Table 1. Classification of human infant thymus ESTs.

\begin{tabular}{lcc}
\hline Classification & Percent & No. of clones \\
\hline Human matched & 50.1 & 613 \\
Non-human matched & 4.2 & 51 \\
EST & 23.6 & 289 \\
rRNA & 4.7 & 58 \\
Alu repeat & 2 & 24 \\
MtDNA & 0.5 & 6 \\
Unknown & 14.9 & 182 \\
Total & 100 & 1223 \\
\hline
\end{tabular}

performed with specific primers against a NIGMS (Coriell Institute for Medical Research, Camden, N.J.) human-rodent somatic cell hybrid mapping panel 2 (Drwinga et al. 1993) and against a GENEBRIDGE 4 RH panel (Research Genetics of Huntsville, Alta.). All PCR reactions were performed in a $50 \mu \mathrm{L}$ volume containing $25 \mathrm{ng}$ of template DNA and $2.5 \mathrm{U}$ of AmpliTaq Gold DNA polymerase (Perkin-Elmer Cetus, Conn.). Cycling parameters were $30 \mathrm{~s}$ at $94^{\circ} \mathrm{C}, 30 \mathrm{~s}$ at $55-60^{\circ} \mathrm{C}$, and $1 \mathrm{~min}$ at $72^{\circ} \mathrm{C}$ for 35 cycles, followed by an additional $7 \mathrm{~min}$ at $72^{\circ} \mathrm{C}$ in a DNA thermal cycler (Perkin-Elmer Cetus). The radiation hybrid scoring data resulting from the PCR screenings were statistically analyzed to localize unknown genes on the framework map using the RHMAPPER program at the Whitehead/MIT center for Genome Research (http://wwwgenome.wi.mit.edu/cgi-bin/contig/rhmapper.pl).

\section{Results and discussion}

\section{Random sequencing and database analysis}

A bidirectional cDNA library was constructed and a total of 1223 ESTs were generated by single-run partial sequencing of over 1400 randomly selected cDNA clones. The average insert size was $0.7 \mathrm{~kb}$ and the average length of sequence was $220 \mathrm{bp}$, which is considered to be useful ESTs. Hillier et al. (1996) reported that the highest quality portion of the EST sequence was between 100 and 300 bases. We classified the results of the database comparisons according to materials and methods. A summary of the database searches for the 1223 sequences is shown in Table 1. Of the 1223 clones, $613(50.1 \%)$ showed significant similarities to human genes and $51(4.2 \%)$ to non-human genes. These 664 clones matching known genes represented 416 unique genes. The other database-matched clones contained $289(23.6 \%)$ ESTs of unknown functions, 24 (2.0\%) Alu-repeats, $58(4.7 \%)$ rRNA, and $6(0.5 \%)$ mitochondrial DNA. The frequencies of $A l u$-like repeats and mitochondrial DNA are significantly lower than those from previous reports (Sudo et al. 1994; Choi et al. 1995). Of the 1223 cDNA clones, $182(14.9 \%)$ were found to be novel transcripts not showing any significant homology to known genes.

The 664 ESTs showing significant homology to known genes were classified into 7 groups according to their functions (Adams et al. 1995); cell signaling-communication, gene-protein expression, cell division-DNA synthesis, cell structure-motility, cell-organism defense and homeostasis, metabolism, and unclassified (Appendix 1). Among these 7 groups, the gene-protein expression group contained the greatest percentage $(34.6 \%)$ of total putative identifications from the infant thymus ESTs. In order to investigate the changes of the gene expression in relation to the aging of the 
thymus, we compared the expression profile of infant thymus ESTs with that of adult thymus ESTs (Adams et al. 1995). Compared to the adult thymus ESTs, the infant thymus ESTs contained a much higher percentage of ESTs that are involved in gene-protein expression and cell divisionDNA synthesis (Fig.1). These differences in the EST profiles between infant and adult thymus' may reflect the active growth state of the infant thymus and involution of thymic tissue with aging. Despite the fact that it is an immunerelated organ, the infant thymus appeared to express a proportion of ESTs for cell-organism defense similar to other organs (Adams et al. 1995) and twice as small as that of the adult thymus. This is likely to indicate that the relatively high levels of ESTs of gene-protein expression and cell division-DNA synthesis in the infant thymus are more closely related to rapid growth than immune function of thymus.

Regarding the EST frequency, eEF-1 a was the most frequently represented in the infant thymus followed by thymosin beta 4 . eEF-1 a was abundantly expressed in cancer, infant tissue, and fetal tissue (Frigerio et al. 1995; Adams et al. 1993b; Hwang et al. 1995; Sudo et al. 1994). Ribosomal proteins also showed high redundancies. Abundant expression of ribosomal proteins was observed in several tissues and differentially expressed in different tissues (Kawamoto et al. 1996; Choi et al. 1995; Tanaka et al. 1996; Frigerio et al. 1995). Consequently, these data coincided with the expression profile of infant thymus ESTs.

We found that some EST sequences corresponding to putative ribosomal proteins (RPs), RTH108 (RP L7a), KTH086 (RP S3), JTH138 (RP S27), and CJC060 (RP S4), showed striking similarities or identities with PLA-X, Fte-1 ( $\mathrm{v}$-fos transformation factor), metallopanstimulin, and the SCAR protein, respectively. Interestingly, the sequence of RTH100 (RP S11) was identical to the antisense sequence of isocitrate dehydrogenase. In 1996, Chan et al. reported that rat ribosomal protein L 10 showed a $99 \%$ and $100 \%$ amino acid identity with a human QM and mouse QM, respectively, and suggested that their data was a presumptive example of the extraribosomal function of the ribosomal protein (Wool 1996).

When we assembled ESTs of unknown functions into a redundant EST group with a TIGR Assembler (Sutton et al. 1995), the group (ThyGR-15) had the highest redundancy ( $n$ =7), which was equal to that of ribosomal L30. Thus, we can assume that the ThyGR-15 group can be considered as a moderately expressed transcript in a human infant thymus.

\section{Chromosome mapping of unknown ESTs}

Forty-three clones were successfully localized onto a human chromosome as the first stage to identify gene-linked genetic disorders (Fig. 2). Of 43 clones, 35 (81.8\%) were mapped onto a single chromosome, 7 (15.9\%) onto 2 chromosomes, and $1(2.2 \%)$ onto 4 chromosomes. Chromosome 6 was most predominantly hit by the infant thymus ESTs. To obtain a more refined map of novel ESTs, 17 clones were screened against a GENEBRIDGE 4 radiation hybrid panel using a PCR-based mapping method and then mapped through the statistical analysis of radiation hybrid mapping data. To survey the ESTs linked to disease loci, the RH maps of thymus ESTs were combined with the cytogenetic map available at the National Center for Biotechnology Information (NCBI).
Fig. 1. Comparison of expression profile of infant thymus ESTs with that of adult thymus ESTs. The 664 ESTs showing significant homology to known genes were classified into 6 groups based on putative functional categories (Appendix 1). After the adult thymus ESTs were extracted from the Genome Directory, the expression profile was compared by calculating the number of the genes of each group of both infant and adult thymus ESTs.

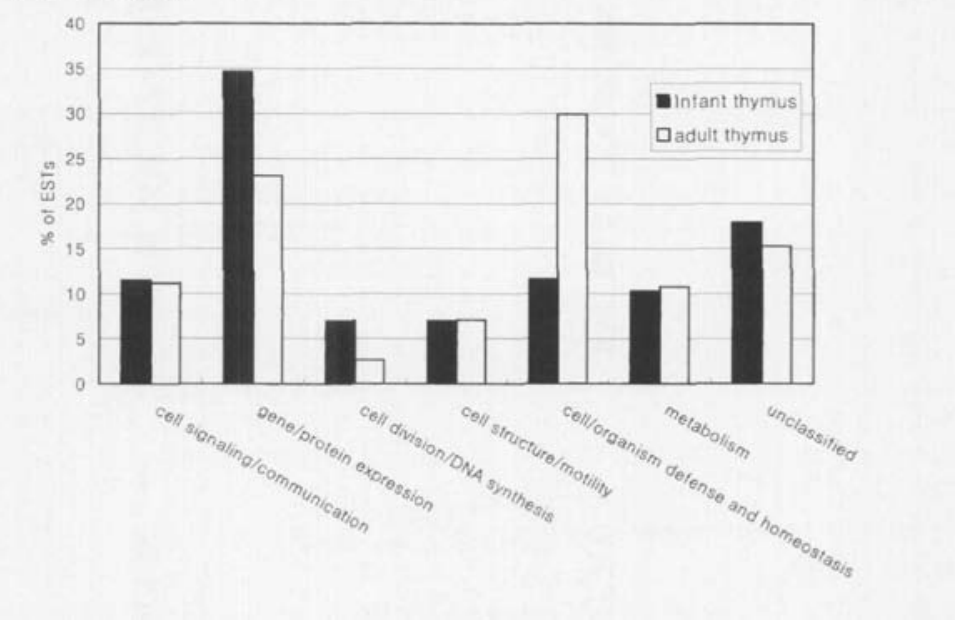

JTH107 placed $6.51 \mathrm{cR}$ from D6S2350, which corresponds to $3 \mathrm{p} 24$ on the cytogenetic map, was linked to the thyroid hormone resistance locus. PTH261 placed $4.81 \mathrm{cR}$ from WI10875 (12q23), which is related to the histidinemia; ATH341 $2.94 \mathrm{cR}$ from D6S442 (6q26) related to the region of plasminogen deficiency I \& II, plasminogen Tochigi disease, and dysplasmingogenic thrombophilla. TH572 was mapped $2.74 \mathrm{cR}$ from D6S455 (6q 14.1) on chromosome 6 (ocular albinism); TH320, 8.12 cR from WI-6400 (2q31.232.1 ) on chromosome 2 (Ehlers-Danlos syndrome, fibromuscular dysplasia of arteries, familiar aneurysm); HTH093, 6.4 cR from CHLCC GATAA 28C02 (9p13.2-13.3) on chromosome 9 (galactosemia); HTH210, $1.71 \mathrm{cR}$ from WI-6355 (11q23.3) on chromosome 11 (hypertriglyceridemia, amyloidosis); HTH167, 4.6 cR from D14S267 (14q32) on chromosome 14 (porphyria variegata); HTH314, $4.19 \mathrm{cR}$ from WI5273 (1p35) on chromosome 1 (Charcot-Marie-tooth disease, galactose epimerase deficiency); PTH056, $6.4 \mathrm{cR}$ from WI-5254 on chromosome 16; ATH209, $40.8 \mathrm{cR}$ from WI4263 on chromosome 12 (FEOM), HTH191, 16.61cR from D15S144 on chromosome 15 (Prader-Willi syndrome), and HTH311, $12.56 \mathrm{cR}$ from WI-6622 on chromosome 20 (neuraminidase deficiency, diabetes mellitus). The combination of EST sequences and map locations are currently in the process of providing numerous new candidate genes for those human pathologies that can be mapped genetically (Boguski and Schuler 1995). Several novel genes from the infant thymus were mapped on to disease loci, including the histidinemia loci, the plasminogen Tochigi disease loci, the Ehlers-Danlos syndrome, the hypertriglyceridemia, etc. Consequently, the radiation hybrid mapping of unknown ESTs from an infant thymus could facilitate the discovery of novel genes involved in genetic diseases or immune disorders. In summary, our cDNA approach enabled us to convert transcripts of a human infant thymus into 1223 expressed sequence tags which featured a high level of genes related to 
Fig. 2. Chromosomal localization of human infant thymus ESTs. The shadow boxes represent the locations of ESTs obtained by radiation hybrid mapping. Diseases linked to these locations are indicated on the left side of each chromosome. When an EST is located on two or more chromosomes, it is represented by an asterisk. Chromosome assignments using a somatic cell hybrid panel are indicated on the bottom of each chromosome with an italic letter.
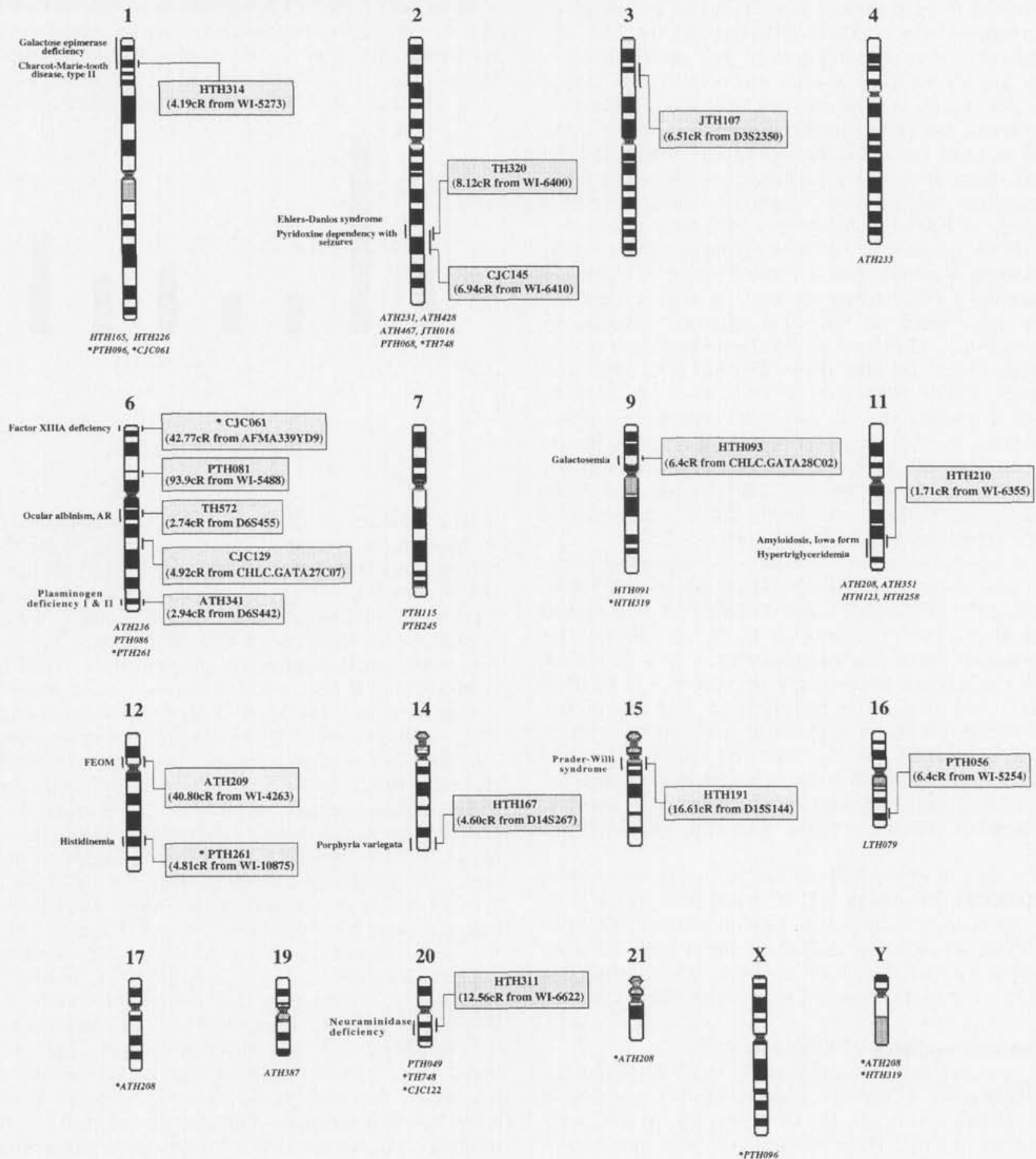

the active cell cycling of thymocytes. The infant thymus ESTs can also be used as useful mapping markers for radiation hybrid mapping in addition to providing the expression information of active genes in the human infant thymus.

\section{Acknowledgements}

This work was supported by grants from the Ministry of Education, the Ministry of Science and Technology of Korea, and the Canadian Genome Analysis and Technology Program. L.-C.Tsui is a Senior Scientist of the Medical Re- 
search Council of Canada, holds the Sellers Chair in Cystic Fibrosis Research, and is a Howard Hughes International Scholar. We would like to thank J.H. Lee, H.C. Lee, J.P. Jeon, J.C. Choi, D.S. Park, and W.K. Cho for their assistance in sequencing.

\section{References}

Adams, M.D., Soares, M.B., Kerlavage, A.R., Fields, C., and Venter, J.C. 1993a. Rapid cDNA sequencing (expressed sequence tags) from a directionally cloned human infant brain cDNA library. Nature Genet. 4: 373-380.

Adams, M.D., Kerlavage, A.R., Fields, C., and Venter J.C. $1993 b$. 3,400 new expressed sequence tags identify diversity of transcripts in human brain. Nature Genet. 4: 256-267.

Adams, M.D., Kerlavage, A.R., Fleischmann, R.D., Fuldner, R.A., Bult. C.J., Lee, N.H., Kirkness, E.F., Weinstock, K.G., Gocayne, J.D., White, O., Sutton, G., Blake, J.A., Brandon, R.C., ManWai, C., Clayton, R.A., Cline, T.R., Cotton, M.D., EarleHughes, J., Fine, L.D., Fitzgerald, L.M., Fitzhugh, W.M., Fritchman, J.L., Geoghagen, N.S., Glodek, A., Gnehm, C.L., Hanna, M.C., Hedblom, E., Hinkle, P.S., Kelley, J.M. Jr., Kelley, J.C., Liu, L.-I., Marmaros, S.M., Merrick, J.M., MorenoPalanques, R.F., McDonald, L.A., Nguyen, D.T., Pelligrino, S.M., Phillips, C.A., Ryder, S.E., Scott, J.L., Saudek, D.M., Shirley, R., Small, K.V., Spriggs, T.A., Utterback, T.R., Weidman, J.F., Li, Y., Bednarik, D.P., Cao, L., Cepeda, M.A., Coleman, T.A., Collins, E.J., Dimke, D., Feng, D.-F., Ferrie, A., Fischer, C., Hastings, G.A., He, W.W., Hu, J.S., Greene, J.M., Gruber, J., Hudson, P., Kim, A.K., Kozak, D.L., Kunsch, C., Hungjun, J., Li, H., Meissner, P.S., Olsen, H., Raymond, L., Wei, Y.F., Wing, J., Xu, C., Yu, G.L., Ruben, S.M., Dillion, P.J., Fannon, M.R., Rosen, C.A., Haseltine, W.A., Fields, C., Fraser, C.M., and Venter, J.C. 1995. Initial assessment of human gene diversity and expression patterns based upon 83 million nucleotides of cDNA sequence. Nature, 377: 3-17.

Affara, N.A., Bentley, E., Davey, P., Pelmear, A., and Jones, M.H. 1994. The identification of novel gene sequences of the human adult testis. Genomics, 22: 205-210.

Altschul, S.F., Gish, W., Miller, W., Myers, E.W., and Lipman, D.J. 1990. Basic local alignment search tool. J. Mol. Biol. 215: 403410.

Berry, R., Stevens, T.J., Walter, N.A.R., Wilcox, A.S., Rubano, T., Hopkins, J.A., Weber, J., Goold, R., Soares, M., And Sikela, J.M. 1995. Gene-based sequence-tagged sites (STSs) as the basis for a human gene map. Nature Genet. 10: 415-423.

Boguski, M.S., and Schuler, G.D. 1995. ESTablishing a human transcript map. Nature Genet. 10: 319-371.

Chan, Y.L., Diaz, J.J., Denoroy, L., Madjar, J.J., and Wool, I.G. 1996. The primary structure of rat ribosomal protein L10: Relationship to a jun binding protein and to a putative Wilms' tumor suppressor. Biochem. Biophy. Res. Commun. 225: 952-956.

Choi, S.S., Yun, J.W., Choi, E.K., Cho, Y.G., Sung, Y.C., and Shin, H.S. 1995. Construction of a gene expression profile of a human fetal liver by single-pass cDNA sequencing. Mamm. Genome, 6 : $653-657$.

Collins, F.S. 1995. Positional cloning moves from perditional to traditional. Nature Genet. 9: 347-350.

Drwinga, H.L., Toji, L.H., Kim, C.H., Greene, A.E., and Mullivor, R.A. 1993. NiGMS human/rodent somatic cell hybrid mapping panel 1 and 2. Genomics, 16: 311-314.
Frigerio, J.M., Berthezene, P., Garrido, P., Ortiz, E., Barthellemy, S., Vasseur, S., Sastre, B., Seleznieff, I., Dagorn, J.C., and Iovanna, J.L. 1995. Analysis of 2166 clones from a human colorectal cancer cDNA library by partial sequencing. Hum. Mol. Genet. 4: $37-43$.

Hillier, L., Lennon, G., Becker, M., Bonaldo, M.F., Chiapelli, B., Chissoe, S., Dietrich, N., DuBuque, T., Favello, A., Gish, W., Hawkins, M., Hultman, M., Kucaba, T., Lacy, M., Le, M., Le, N., Mardis, E., Moore, B., Morris, M., Parsons, J., Prange, C., Rifkin, L., Rohlfing, T., Schellenberg, K., Soares, M.B., Tan, F., Thierry-Meg, J., Trevaskis, E., Underwood, K., Wohldman, P., Waterston, R., Wilson, R., and Marra, M. 1996. Generation and Analysis of 280,000 Human expressed sequence tags. Genome Res. 6: $807-828$.

Hwang, D.M., Fung, Y.W., Wang, R.X., Laurenssen, C.M., Ng, S.H., Lam, W.Y., Tsui, K.W., Fung, K.P., Waye, M., Lee, C.Y., and Liew, C.C. 1995. Analysis of expressed sequence tags from a fetal human heart cDNA library. Genomics, 30: 293-298.

Kawamoto, S., Matsumoto, Y., Mizuno, K., Okubo, K., and Matsubara, K. 1996. Expression profiles of active genes in human and mouse livers. Gene, 174: 151-158.

Kirkness, E.F. 1996. Assessment of human gene diversity and expression pattern using expressed sequence tags. Essays in Biochem. 31: 1-9.

Lamerdin, J.E., Athwal, R.S., Kansara, M.S., Sandhu, A.R., Patanjali, S.R., Weissman, S.M., and Carrano, A.V. 1995. Chromosomal localization and expressed sequence tag generation of clones from a normalized human adult thymus cDNA library. Genome Res. 5: 359-367.

Lee, N.H., Weinstock, K.G., Kirkness, E.F., Earle-Hughes, J.A., Fuldner, R.A., Marmaros, S., Glodek, A., Gocayne, J.D., Adams, M.D., Kerlavage, A.R., Fraser, C.M., and Venter, J.C. 1995. Comparative expressed-sequence-tag analysis of differential gene expressed profiles in PC-12 cells before and after nerve growth factor treatment. Proc. Natl. Acad. Sci. U.S.A. 92: 8303-8307.

Liew, C.C., Hwang, D.M., Fung, Y.W., Laurenssen, C., Cukerman, E., Tsui, S., and Lee, C.Y. 1994. A catalogue of genes in the cardiovascular system as identified by expressed sequence tags. Proc. Natl. Acad. Sci. U.S.A. 91: 10645 - 10649.

Okubo, K., Itoh, K., Fukushima, A., Yoshii, J., and Matsubara, K. 1995. Monitering cell physilogy by expression profiles and discovering cell type-specific genes by compiled expression profiles. Genomics, 30: 178-186.

Sambrook, J., Fritsch, E.F., and Maniatis, T. 1989. Molecular cloning: A laboratory manunual. 2nd ed. Cold Spring Harbor Laboratory Press, Cold Spring Harbor, New York.

Sudo, K., Chinen, K., and Nakamura, Y. 1994. 2058 expressed sequence tags (ESTs) from a human fetal lung cDNA library. Genomics, 24: 276-279.

Sutton, G.G, White, O., Adams, M.D., and Kerlavage, A.R. 1995. TIGR Assembler: A new tool for assembling large shotgun sequencing projects. Genome Sci. \& Tech. 1: 9-19.

Tanaka, T., Ogiwara, A., Uchiyama, I., Takegi, T., Yazaki, Y., and Nakamura, Y. 1996. Construction of a normalized directionally clones cDNA library from adult heart and analysis of 3040 clones by partial sequencing. Genomics, 35: 231-235.

Wool. I.G. 1996. Extraribosomal functions of ribosomal proteins. Trends Biochem. Sci. 21: 164-165. 
Appendix 1. Infant thymus ESTs matched to known genes in the database.

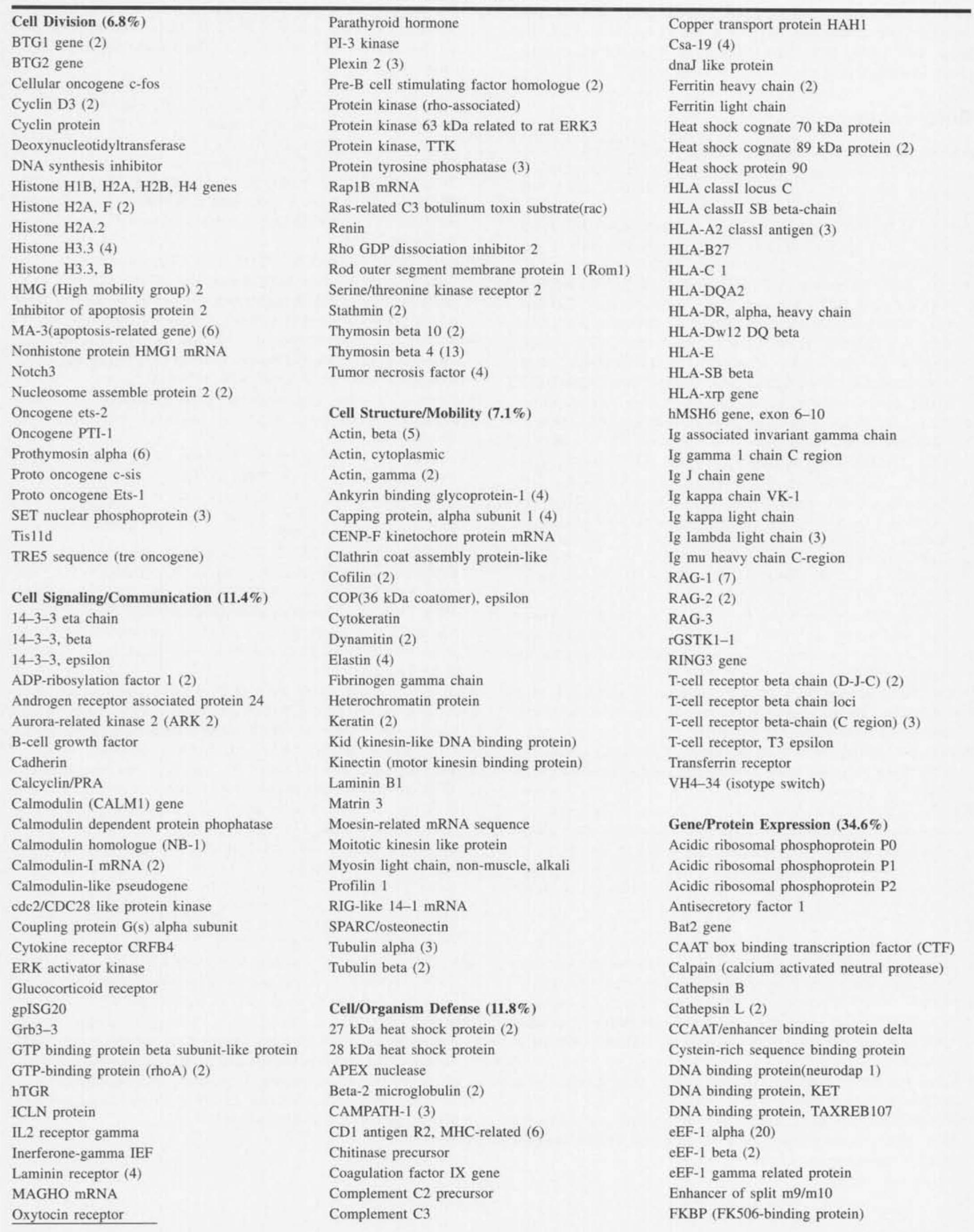


Appendix 1 (continued).

\begin{tabular}{|c|c|c|}
\hline G17 gene & Ribosomal protein S27 (2) & ATPase, $\mathrm{H}+$ transport, vacuolar $(2)$ \\
\hline Helicase (218kD Mi-2 protein) (2) & Ribosomal protein S28, yeast homolog & ATPase, NA + / K+ transport, alpha subunit \\
\hline Helix-loop-helix-leucine zipper (SREBP-1) & Ribosomal protein S29 & ATPase, proton subunit D, vacuolar (3) \\
\hline Heterogenous ribonucleoprotein homolog (3) & Ribosomal protein S2a & Co-beta glucosidase(proactivator) \\
\hline Hlark mRNA & Ribosomal protein S3a (6) & CYP3B6 gene cryptic exon (cytochrom p450) \\
\hline hnRNP core protein A1 & Ribosomal protein S4 (2) & Cytochrome C oxidase polypeptide I (COX I) \\
\hline$h n R N P D(2)$ & Ribosomal protein S5 & Cytochrome C oxidase subunit IV (COX 4) \\
\hline hnRNP-C & Ribosomal protein S6 & Cytochrome $\mathrm{c}$ oxidase subunit VIa \\
\hline hnRNP-C2 & Ribosomal protein $\mathrm{S} 7$ & Cytochrome $\mathrm{C}$ oxidase subunit Vib \\
\hline hnRNP-E1 (2) & Ribosomal protein S8 (2) & Cytochrome C oxidase subunit VIIb \\
\hline hnRNP-H & Ribosomal protein $\mathrm{S} 9$ & Deoxycytidine kinase (3) \\
\hline hnRNP-K & Ribosomal protein YL30 & Enyol CoA dehydrogenase \\
\hline MAD-3 encoding IkB-like acitivity & RNA binding protein, $\mathrm{HU}-\mathrm{K} 4$ & Glycealdehyde-3-phosphate dehydrogenase \\
\hline Myocyte specific enhancer factor (2) & RNA helicase \#46, ATP-dependent & GTP cyclohydrolase I \\
\hline Nuclear p68 protein (3) & RNA polymerase I & Iduronate sulphate sulphatase (IDS) \\
\hline Plasminogen activator inhibitor-1 & Seb4 & Importin beta subunit \\
\hline Polyadenylation specificity factor & Sec61(protein transport protein) & Inosine monophosphate dehydrogenase type II \\
\hline Prolyl 4 hydroxylase, alpha subunit (4) & SOX-4 (Sry-like HMG box protein) & Lactate dehydrogenase A \\
\hline Proteasome component $\mathrm{C} 9$ & Splicing factor mRNA & Lactate dehydrogenase B \\
\hline Proteasome related gene (LMP 2) & Splicing factor SRp75 & Liver phosphatase $2 \mathrm{~A}(2)$ \\
\hline Proteasome subunit $\mathrm{HC} 8(2)$ & Splicing factor, SF1-HL1 isoform & Lysophosphatidic acid acyltransferease-alpha (2) \\
\hline Proteasome subunit p55 & SW1/SNF complex $155 \mathrm{kDa}$ subunit (BAF155) & Malate dehydrogenase \\
\hline Proteasome-like subunit & TCF-1 (T-cell specific transcription factor) & mGLT(glutamate transporter)-1 mRNA \\
\hline putative RNA binding protein & TFIID $55 \mathrm{kDa}$ subunit & Monocarboxylate transporter 1 (2) \\
\hline Ribosomal protein $\mathrm{L} 1$ & TFIIB mRNA & Muscle glycogen phosphorylase \\
\hline Ribosomal protein L10 (3) & Transcription factor (Staf 50) & $\mathrm{N}$-acetylglucosaminyltransferase III DNA, \\
\hline Ribosomal protein $\mathrm{L} 17$ & Transcription factor AF-1p & NAD $(P)+$ dependent malic enzyme mRNA (2) \\
\hline Ribosomal protein L21 (2) & Transcription factor, ASF & NADH:ubiquitin oxidoreductase \\
\hline Ribosomal protein L23 (5) & Transglutaminase type I & Nm23 protein (nucleoside diphosphate kinase) \\
\hline Ribosomal protein L24 & Translation factor Suil homolog (3) & Oligoadenylate synthetase \\
\hline Ribosomal protein L26 (4) & Translation initiation factor $\mathrm{p} 40$ subunit & Phospholipase A2 \\
\hline Ribosomal protein L27 (2) & Translation initiation factor 3 & Phosphotyrosyl phosphatase activator \\
\hline Ribosomal protein L28 (2) & Translation initiation factor, Eif $4 \mathrm{~g} 2$ & Purin 5'-nucleotidase \\
\hline Ribosomal protein L3 (2) & Translation repressor NAT1 mRNA (7) & r-aminobutylaldehyde dehydrogenase \\
\hline Ribosomal protein L30 (7) & $\mathrm{U} 21.1 \mathrm{hnRNP}$ & Ribonuclease 6 precursor \\
\hline Ribosomal protein L32 & Ubiquitin (2) & Ribonucleoside diphosphate reductase M1 \\
\hline Ribosomal protein L35 (4) & Ubiquitin conjugating enzyme (ubc4) & Ribonucleotide reductase M2 \\
\hline Ribosomal protein L36 & Ubiquitin conjugating enzyme E2 (2) & Secretory carrier membrane protein \\
\hline Ribosomal protein L37 (3) & USF-2(upstream stimulatory factor-2) & sterol carrier protein (3) \\
\hline Ribosomal protein L37a & Wilm's tumor-related protein (6) & Ubiquinal-cytochrome $\mathrm{C}$ reductase \\
\hline Ribosomal protein L38 & Zinc finger protein RING (RZF) & \\
\hline Ribosomal protein $\mathrm{L} 4$ & Zinc finger protein, HPF1 (3) & Unclassified $(17.9 \%)$ \\
\hline Ribosomal protein L41, yeast homologue & Zinc finger protein, ZNF & $23 \mathrm{KD}$ highly basic protein(Ig gamma) \\
\hline Ribosomal protein L44, yeast homologue & & AICL(activation induced c-type lectin) \\
\hline Ribosomal protein L5 (3) & Metabolism (10.4\%) & Ataxia telagiectusa (ATM) gene \\
\hline Ribosomal protein L6 & 2 ' oxidoglutarate dehydrogenase & Autoantigen DFS70 \\
\hline Ribosomal protein L7 (2) & Adenosin Deaminase (ADA) & $\mathrm{BBC} 1$ (breast basic conserved) protein \\
\hline Ribosomal protein L7a (3) & Adenosin monophosphate deaminasel & Beta amyloid protein(APP) gene \\
\hline Ribosomal protein L9 (4) & Adenosine triphosphatase & Brain 0-44 mRNA \\
\hline Ribosomal protein S10 (3) & Aldehyde dehydrogenase & BRCA2(breast cancer susceptibility) \\
\hline Ribosomal protein S11 (6) & Alpha enolase gene (2) & CG1 protein \\
\hline Ribosomal protein S14 (3) & Apolipoprotein A-IV gene & CLE7 (G.gallus) (3) \\
\hline Ribosomal protein S16 & ATP synthase, beta subunit (2) & COX7RP \\
\hline Ribosomal protein S17 (2) & ATP synthase, gamma subunit (2) & CpG DNA (5) \\
\hline Ribosomal protein S18 (4) & ATP synthase, subunit a & Dead box, $x$ isoform(DBX) alternative transcript 2 \\
\hline Ribosomal protein S20 (4) & ATP synthase, subunit $\mathrm{c}(2)$ & Down syndrome region \\
\hline Ribosomal protein S24 (2) & ATP synthase, subunit d & DT1P1A10, CAG repeat \\
\hline RIbosomal protein S25 (2) & ATP synthase, subunit $f$ & DT1P1A2, CAG repeat \\
\hline Ribosomal protein S26 (2) & ATP synthase, subunit $g$ & Duffy blood group antigen Fya-b+ \\
\hline
\end{tabular}


Appendix 1 (concluded).

\begin{tabular}{|c|c|c|}
\hline E25 mRNA ( 2$)$ & Hypothetical protein, KIAA0161 gene & Nuclear Factor IV \\
\hline EB virus small RNA associated protein (EAP) & Hypothetical protein, KIAA0217 gene & Nucleolar phosphoprotein B23(nucleophomin) \\
\hline EBI1-ligand chemokine (ELC) & Hypothetical protein, KIAA0220 gene & Nucleolar protein P120(ribonucleoprotein) \\
\hline GP91-PHOX gene promoter region & Hypothetical protein, KIAA0252 gene & Ocular melanoma associated antigen \\
\hline GRSF-1(G-rich sequence factor-1) & Hypothetical protein, KIAA0261 gene & ORF mRNA \\
\hline GT233 mRNA & Hypothetical protein, KIAA0323 gene & $\mathrm{p} 38-2 \mathrm{G} 4$ \\
\hline HE5 (CDw52-like epididymal protein) (5) & IEF7422 & Proliferation-associated protein pag \\
\hline Heat shock protein hsp70 & Interferon inducible gene (3) & Prostatein $\mathrm{C} 3$ subunit gene \\
\hline Hepatocyte nuclear factor 1 promoter & JKA10 mRNA induced upon T-cell activation & putative nuclear pore complex protein(Npap60) \\
\hline HepG2 3' region cDNA & Leucine rich protein & PxF protein $(3)$ \\
\hline HLA class III containing NOTCH4 gene (2) & LLReps 3 & Retinoblastoma produt binding protein (RBQ-1) \\
\hline Housekeeping & LTG9/MLLT3, C-terminal & Retroposon SINE-R11 (2) \\
\hline Human farmilial Alzheimer's disease gene & Lymphoid restricted membrane proein, Jaw1 & S153 clone mRNA \\
\hline Human mRNA for 3-7 gene product & Lysosomal-associated membrane glycoprotein 1 & Serine-rich neutrophil protein \\
\hline Huntington's disease region & Lysosome associated membrane protein 2 & Split hand/split foot 1 (DSS1) (3) \\
\hline Hypothetical protein, KIAA0034 gene (3) & Melanoma associated antigen & T-cell surface glycoprotein E2 \\
\hline Hypothetical protein, KIAA0037 gene & Metallopanstimulin 1 & Tera mRNA \\
\hline Hypothetical protein, KIAA0040 gene & MGC-24 (PNA-binding protein) & Thymocyte antigen CD1b \\
\hline Hypothetical protein, KIAA0040 gene & MHC class I HLA-C 1 gene & Transformation related protein (2) \\
\hline Hypothetical protein, KIAA0045 gene & MHC class I HLA-C 1 locus $C$ heavy chain & Transmembrane protein (4) \\
\hline Hypothetical protein, KIAA0083 gene & $\mathrm{Na}+/ \mathrm{H}+$ exchang regulatory co-factor & Unknown antigen \\
\hline Hypothetical protein, KIAA0101 gene & NAC, alpha (4) & Unknown protein within p53 intron 1 \\
\hline Hypothetical protein, KIAA0107 gene & NifU-like protein (hNifU) mRNA & Xl1gene \\
\hline Hypothetical protein, KIAA0128 gene & Ninein (centromal protein) & XG blood group \\
\hline Hypothetical protein, KIAA0159 gene & NK-tumor recognition molecule-related protein & ZFM 1 protein alternatively spliced product \\
\hline
\end{tabular}

Note: Human infant ESTs matching to 416 distinct known genes were divided into 7 groups according to the putative function (Adams et al. 1995). Numbers in parentheses indicate the frequency of the ESTs. In the case of non-human matched ESTs, the organism is indicated in parentheses. 